\title{
Diversity and Abundance of Marine Plankton and Benthos of Maruthankerny, Off Jaffna, Sri Lanka
}

\author{
Jayasiri H.B. ${ }^{*}$, Dahanayaka D.D.G.L. and Arulananthan K. \\ National Aquatic Resources Research and Development Agency, Sri Lanka \\ *hbjayasiri@gmail.com
}

\begin{abstract}
The distribution of plankton and macrobenthos along the coasts from the Northern and NorthEastern to South-Eastern is virtually unknown. Therefore, present study was carried out to determine the species composition, abundance and distribution of marine plankton and benthos off Jaffna, Sri Lanka to enhance the knowledge on biodiversity of this coastal environments.
\end{abstract}

Field survey was conducted during February 2016. Benthic samples with triplicate were collected from selected 18 locations at Maruthankerny, Jaffna using a Peterson grab and immediately fix using $10 \%$ formalin. The benthic samples were subjected to wet sieving through $500 \mu \mathrm{m}$ mesh sieve to separate the benthic fauna from the substrate. The organisms retain in the sieve were collected and preserved in $70 \%$ alcohol and identified up to the lowest possible taxonomic level. Vertical hauls of zooplankton and phytoplankton were collected from 12 locations using plankton nets with mesh sizes of $100 \mu \mathrm{m}$ and $10 \mu \mathrm{m}$ respectively. The zooplankton and phytoplankton samples were immediately fixed with 5\% formalin and Lugol's solution respectively. In the laboratory, one milliliter of each sample was placed on the Sedgewick rafter counting chamber and organisms were identified and enumerated using a binocular microscope.

Twenty six (26) species of polychaetes, 9 species of crustaceans, 15 species of gastropods, 12 species of bivalves and 2 species of echinodermates were recorded in benthic samples. The most abundant group of macrobenthos was polychaetes, which contributed for $45.25 \%$ of total macrobenthic community, followed by mollusks $(35.51 \%)$. The phytoplankton analysis showed that abundance varied from 279 to 866 No./L with a mean of 554 201 No./L. A total of 92 taxa were reported from the area. Sixty eight (68) taxa were identified as diatoms, while 24 taxa were belonged to dinoflagellates. Diatoms accounted for $93.97 \%$ of the total phytoplankton population at the area followed by dinoflagellates (6.03\%). Most dominant phytoplankton taxa was Chaetoceros sp. which contributed $33.70 \%$ of the total population followed by Bacteriastrum (16.24\%). Species richness of phytoplankton in the area varied from 48-68 with a mean 55.83 \pm 5.70 . Zooplankton abundance varied from 36 to 385 indivi. $\mathrm{L}^{-1}$ with a mean of $91.57 \pm 46.02$ indivi. $\mathrm{L}^{-1}$ in the study area. Most dominant group was copepods, which comprised $52.87 \%$ followed by crustacean larvae (nauplii, 9.89\%). Most common zooplankton species were Calanus sp. (10.01\%), Oithona sp. (6.89\%), Paracalanus sp. (4.19\%) and Oithona aculata (3.97\%).

Keywords: Phytoplankton, Zooplankton, Macrobenthos, Jaffna, Sri Lanka

Proceedings of the International Forestry and Environment Symposium 2016, Department of Forestry and Environmental Science, University of Sri Jayewardenepura, Sri Lanka. 